\title{
Augmented Reality For Education
}

Professor Debbie Holley, Dr Mike Hobbs,

Bournemouth University, Bournemouth, Dorset

E-mail dholley@bournemouth.ac.uk; mhobbs@bournemouth.ac.uk

Corresponding dholley@bournemouth.ac.uk;

\section{Introduction}

Reimagining our future engagement with learners through an augmented reality (AR) lens offers a range of possibilities, on a continuum from rigid materials, created with generic learning outcomes, to learner-centred, personalised and emancipatory practice. Educational paradigms are shifting to include alternatives to physical classrooms and the controlled virtual learning spaces that support traditional content delivery. Augmented reality is part of a broader mixed reality where varying degrees of virtual enhancement to the real world can be integrated into traditional delivery practice but also allow learning spaces to be explored more imaginatively and collaboratively.

For educators, there are significant challenges to utilise the potential of technology to meet the increasing demands of students, institutions, industry and the expectations of society. By carefully scaffolding educators into reframing their curricula to encourage, inspire and motivate a diverse student body, technology can act as a mediator - a proxy for what Vygotsky termed the 'more capable peer' (Cook 2010). AR applications in education, training, marketing, medicine and other industries demonstrate both the capability of the technology and the need for designers to be aware of the possibilities. Karakus et al (2019), in their bibliometric study of augmented reality in education, identify the work by Wu et al (2013) as the most influential across the sector. This paper suggests that AR not only bridges virtual and real worlds but alsocreates an enhanced reality through a creative process. They argue that the educational values of AR are not solely based on the use of technologies but are closely related to how AR is designed, implemented and integrated into formal and informal learning settings.

The recent McKinsey report (Bughin et al, 2018) modelled skills shifts in automation and artificial intelligence going forward to 2020 and found a sharp acceleration in demand for these technologies that will transform the workplace, as humans work with ever smarter machines. Transferring technology for educational use, re-use and re-purpose are key emergent themes in research as employers demand ever more technology enabled graduates, with high-level cognitive skills.

\section{AR Definition and General Mechanisms}

The 'augmented' term of augmented reality (AR) has its origins from an essay written by Sutherland (2009) where the author predicts:

"There is no reason the objects displayed by a computer have to follow the ordinary rules we are familiar with ...the user of a visual display could easily make solid objects transparent. He can 'see through matter' [with] augmented reality urbanware"

The term was first used to describe technology by Tom Caudell in 1990 while working on ways to visualise component information in aircraft construction at Boeing. In common with other virtual 
technologies, experimental prototypes were developed during the 1990s, with the first AR system developed by Louis Rosenberg at the US Air Force Research Laboratory in 1992.

Today there are a variety of devices and technologies but most users experience AR as an application on their smartphone to display media combined with the image of the real world on their screen. Typically, the media is triggered by scanning objects or images that match a previously captured image of the scene. Other triggers include dedicated logos, QR codes, location sensors, or system generated events such as responses to user queries, display of data streams or timed events. It is with these broader considerations in mind we move to the affordances of $A R$ and the benefits and barriers to adoption in a range of learning contexts.

\section{Affordances and Application Areas}

The defining feature of AR is that it is context sensitive, aware of its temporal, spatial, physical and virtual environment, operating at a specific time (temporal), place (spatial), and in response to particular / pre-determined real time triggers (physical), or data input (virtual). In common with other virtual environments, it can respond to user interaction and direction so that the experience can be unique to the user. There are many applications of AR, but these can be usefully categorised into three broad and overlapping areas - content delivery, user content creation and data integration.

Many applications use AR to allow the visualization and 3D exploration of remote or difficult to see structures or components, which makes it ideal for content delivery and experiential learning in engineering, science, medicine, environment, architecture and historical education.

In common with previously innovative, disruptive technologies, AR is extending from specialised developers and professional publishers to include hobbyists and casual creators within social media. Ranging from basic image filters to more sophisticated AR shopping experiences and development studios, Snapchat, Facebook and Instagram are providing users with AR creation and sharing facilities. This provides considerable opportunity for educationalists to develop collaborative projects that allow students to create and share their own artefacts in many different learning contexts.

A more technically advanced use combines image recognition with data analysis, enabling prototype systems to automatically identify triggers and associate overlay information; enabling large-scale integration of AR with existing information resources. Using AR as part of data analysis and visualisation can help illustrate and interpret results. For example, blood circulation data can be projected onto a patient's body to show blood flow issues from diseases such as diabetes; the inside of a nuclear reactor comes to life; teams working at critical incidents such as fire crews can 'see' how flames proliferate inside a building.

\section{Augmented Technology}

$A R$ is made up of several continually developing technologies that fit within a continuum of virtualisation from none (real world) to complete (virtual world), as shown in Figure 1 where augmented reality and augmented virtuality are also known as 'mixed' reality. 


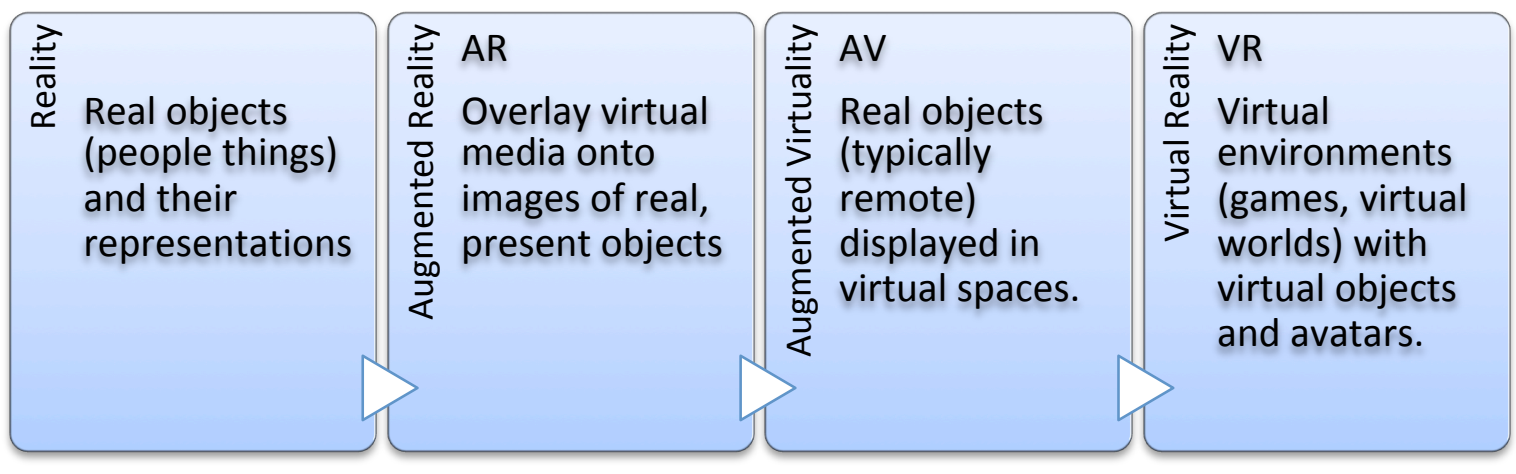

Figure 1. Technologies within the mixed virtual continuum

\section{Viewing AR}

Figure 2 shows representative examples of the main viewing display devices. The simplest AR devices are smart phones or tablets running an AR app. These can be used handheld or with a viewer such as Google Cardboard, or one of the many similar products that support the device in a headset with lenses to provide a 3D view. Coupled with a free version of an AR app students can use their own devices making it possible to engage in AR use and content creation without the need for expensive equipment and software.

Although the original Google Glass was seen as a breakthrough it has not been a commercial success. However, there are a wide range of heads-up display glasses that project media onto the surface of the lens and provide different levels of interaction - from simple audio, to sophisticated interactive media and dedicated controllers for remote devices such as drones. Processing power is often provided by mobile phone to provide an intermediate platform between a handheld device and a full headset.

Headsets designed for VR and gaming (such as Oculus, HTC Vive, Samsung Gear and Sony PlayStation VR) have been adapted for AR but need to provide a camera facility to capture the real world to enable augmentation. Many of these require a high-speed data link to a sufficiently powerful computer or game console, which provides good quality graphics but limits their mobility. More sophisticated versions come with their own image processing capability.

An indication of the direction of technological development is shown by the Magic Leap, which has been designed for AR with lenses embedded in a wraparound headset. This has a pocket-sized processing pack and uses sensors for gesture control, object location and accurate image overlay. The Microsoft Holo Lens uses an on-board computer for gesture control sensors and to project images onto a transparent screen to combine the virtual with the real-world view. It has shown potential for AR based collaboration allowing participants from different locations to interact with 3D models for engineering and medical projects. 


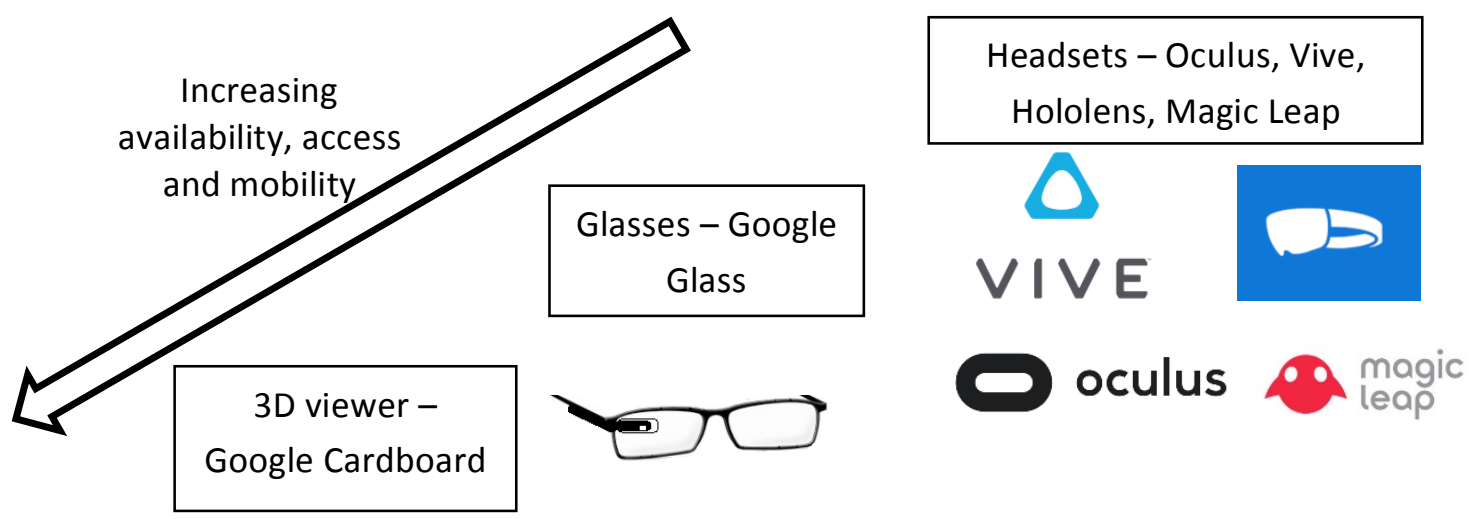

Phone / tablet
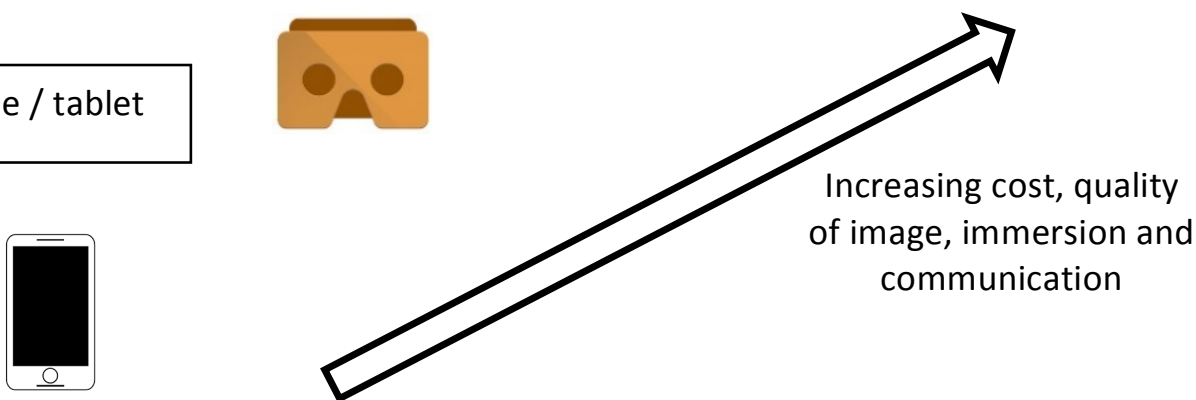

of image, immersion and

communication

Figure 2. AR viewing devices

\section{Using and Creating AR}

There are four broad groups of AR viewing apps and development systems available to users and developers. Standalone AR apps provide a dedicated experience for users. Generic AR systems are designed to allow novices, as well as professionals, to create and share content from different authors using that technology. More sophisticated software development systems require coding skills and provide tools for importing from, and exporting to, different third-party systems. These are used by independent developers and commercial companies to create stand alone apps. Finally, AR is being taken up by social media companies who are increasing the range of features supported for casual users and providing their own application development environments. This is especially significant as it marks the progression of AR from a novelty into the mainstream and provides easy access to a previously restricted mode of expression. Table 1 shows an indicative list of some of the more common development environments but, given the rate of change of technology, this is a representative snapshot rather than a definitive classification. 


\begin{tabular}{|c|c|c|}
\hline System & Significant features & Application areas \\
\hline \multicolumn{3}{|c|}{$\begin{array}{l}\text { Systems with free app for viewing, suitable for user created content from non-experts, with } \\
\text { mobile app and web-based studio }\end{array}$} \\
\hline $\begin{array}{l}\text { HP-Reveal } \\
\text { (Aurasma) } \\
\text { www.hpreveal.com }\end{array}$ & $\begin{array}{l}\text { Easy install and link to content } \\
\text { from QR or URL }\end{array}$ & PR, Marketing, casual users \\
\hline $\begin{array}{l}\text { Layar } \\
\text { www.layar.com }\end{array}$ & $\begin{array}{l}\text { Monthly hosting fee, } \\
\text { educational discount }\end{array}$ & Print, magazines and catalogues \\
\hline $\begin{array}{l}\text { Zappar } \\
\text { www.zappar.com }\end{array}$ & $\begin{array}{l}\text { ZapBox - Cardboard headset, } \\
\text { controllers and trigger cards. }\end{array}$ & $\begin{array}{l}\text { Retail, packaging, publishing and } \\
\text { education }\end{array}$ \\
\hline $\begin{array}{l}\text { Blippar } \\
\text { www.blippar.com }\end{array}$ & $\begin{array}{l}\text { Campaign management user } \\
\text { tracking. }\end{array}$ & Marketing, Higher Education \\
\hline \multicolumn{3}{|c|}{$\begin{array}{l}\text { Systems for technically able students or support staff, code-based application development } \\
\text { and professional system development }\end{array}$} \\
\hline $\begin{array}{l}\text { ARCore } \\
\text { developers. } \\
\text { google.com/ar/ }\end{array}$ & $\begin{array}{l}\text { Google API integrates input } \\
\text { from many sources, targets } \\
\text { different systems. }\end{array}$ & $\begin{array}{l}\text { Independent AR application } \\
\text { developers }\end{array}$ \\
\hline $\begin{array}{l}\text { Apple ARkit } \\
\text { developer. } \\
\text { apple.com/arkit }\end{array}$ & $\begin{array}{l}\text { Multiple users, persistent } \\
\text { sessions, object tracking }\end{array}$ & $\begin{array}{l}\text { Independent AR application } \\
\text { developers }\end{array}$ \\
\hline $\begin{array}{l}\text { Augment } \\
\text { www.augment.com }\end{array}$ & $\begin{array}{l}\text { Accurate and persistent AR } \\
\text { artefact location }\end{array}$ & E-commerce, sales, education \\
\hline $\begin{array}{l}\text { Wikitude } \\
\text { www.wikitude.com }\end{array}$ & $\begin{array}{l}\text { Geo-location, 3D scene } \\
\text { recognition, object tracking, } \\
\text { browser interface }\end{array}$ & $\begin{array}{l}\text { Bespoke and commercial AR } \\
\text { creation }\end{array}$ \\
\hline $\begin{array}{l}\text { Vuforia } \\
\text { www.vuforia.com }\end{array}$ & $\begin{array}{l}\text { Integration with } 3 D \text { systems, } \\
\text { trigger AR with location, card, } \\
\text { image or object. }\end{array}$ & $\begin{array}{l}\text { Independent AR application } \\
\text { development }\end{array}$ \\
\hline
\end{tabular}

Table 1 Representative selection of AR systems and tools

\section{Augmented Reality for Learners: Examples of the Learner Experience}

The affordances of AR support a range of pedagogical approaches when designing a learning experience. Place-based learning, encouraging learners to make their thinking more visible, and team-based approaches to professional development help engage the learner in an active learning context (Ferguson et al, 2019).

$A R$ is particularly suited for use within a scaffolded programme. It gives an element of novelty, encourages exploration and focuses on the individual experience; developing a deeper understanding of the concepts, while providing a stimulating, collaborative, problem-solving environment. It provides a platform to engage students with learning at a place and time of their choosing; moving outside the confines of the formal lecture theatre and changing our practices in supporting their learning. These principles can be seen in the Hobbs and Holley (2016) case study; 
this describes the re-energising of a cohort of computer science students who were struggling with the personal development planning (PDP) assessed component of a core unit. By undertaking a radical curricula review, the weekly didactic lecture was transformed to a co-created, dynamic, student led space. Students in small groups were required to create a team name with a logo and an augmented reality artefact (an Arasma 'aura') to engage with the University Library. They then planned, scripted and storyboarded a short video overlay for their aura, which echoed and linked to core themes from software and game design. Over a three-year period, the progression rate moved from $66 \%$ to $91 \%$, working with 345 students; the biggest single factor was that the authentic aspects of the AR tasks aligned with student expectations for the context of the soft skills they were practicing. Thus learner-centred and personalised approaches to learning were supported by the affordances of AR. Feedback showed that the learners were motivated, inspired and challenged by this different model of learning.

AR offers educators and their learners opportunities to personalise pedagogical practices through the use of content specific apps, an early example was 'The 3D Interactive Augmented Realty Coloring Book', introduced at the IEEE 3D symposium by Clark and Dünser in 2012. This exploited the affordances of $A R$ and offered ways for educators to work with groups who struggle to access a school-based curriculum. Originally trialled with primary school classes in mind, the principles can be applied to agile design and 3D modelling for non-experts. Another way of using AR is to embed it into learning / play activities, using objects or cards as triggers in an otherwise relatively unstructured play environment to create 'educational magic toys'.

At California State University, AR was used with GPS sensors to simulate geology expeditions for students at five institutions who were able to engage with a meaningful geological learning experience, without having to travel hundreds of miles to the Grand Canyon. This is an example of AR facilitating experiential learning outside the normal environment of the classroom.

Bespoke systems use specialised equipment or combine existing systems in novel ways. For example, the 'Starry Sky' exploration system created by Shanghai University, demonstrates AR used within a complete learning system built with the aim of teaching primary school students about the solar system; this includes video and interactive gaming as well as mobile devices to scan ID cards that support instructor based learning in the classroom. This illustrates how AR can be integrated with other teaching methods such as gamification.

Creative AR systems aimed specifically at education, enable the creation and sharing of AR materials and provide more support than generic systems, which are mostly developed for marketing and promotional uses. For example, 'Augment' provides a platform for building and presenting 3D models in a range of topics. These systems provide a more problem-based approach involving design and construction of artefacts.

In industry, AR is used to provide support when / where needed by augmenting tools and infrastructure to demonstrate emergency procedures and how to use and maintain equipment. It can be used to supplement traditional training by using AR activities and context sensitive materials. The British Safety Council uses AR in its training courses as it provides a safe environment for 
realistic, complex problems and they say it has increased retention of information and the enjoyment of the learning experience.

Medicine has pioneered the use of AR for medical training (Barsom et al, 2016) and is also using it to support medical procedures such as finding veins for IV insertion and overlays to project scanning information and tissue identification during surgery. The Microsoft HoloLens has been used to locate bones and blood vessels during lower limb surgery at Imperial College. Examples such as these demonstrate how AR is not just an educational tool, but is also relevant to industry and career skills, which can help to motivate students and provide more authentic learning experiences.

Sophisticated applications of AR are not confined to high tech industry. At the North Western University Knight Lab, journalism students create AR visualisation within projects designed to incorporate 3D AR visualisation within their work to explain complex concepts and provide a different perspective on narrative creation.

\section{Concluding comments}

The development of AR as a meaningful educational technology aligns with the pedagogic and economic imperatives to personalise the student experience. Responding to the changing landscape of Higher Education (HE) requires the development of imaginative approaches to support staff in delivering quality learning experiences with their students. AR and its affordances can make a significant impact, as part of a mixed-media strategy, to the holistic student experience. Wang et al (2018) and Akçayır (2017) provide reviews of current educational practice with AR, showing that it is being used in both technical and more general educational contexts. Clearer proof of efficacy, such as these, should improve scalability of these technologies and convince academics that investing their time and faculty money in these technologies is appropriate in bridging the passive/active learning continuum, as well as offering a conduit for the industry/academic cross overs. AR offers spaces for digital making, creating, sharing and curating and thus can disrupt traditional pedagogic frameworks. AR has huge potential in terms of disrupting existing pedagogical frameworks, and offering shared and co-created spaces for digital making, creating, sharing and curating.

\section{References}

Akçayır, M., Akçayır, G. (2017). Advantages and challenges associated with augmented reality for education: A systematic review of the literature. Educational Research Review, 20, 1-11

Barsom, E.Z., Graafland, M., Schijven, M.P. (2016). Systematic review on the effectiveness of augmented reality applications in medical training, Surg Endosc 30: 4174. 10.1007/s00464016-4800-6J.

Bughin, J., Hazen, E., Lund, S., Dahlstrom, P., Wiesinger, A., Subramaniam, A. (2018). Skill Shift Automation and the future of the workforce, McKinsey Global Institute Discussion Paper. https://www.mckinsey.com/featured-insights/future-of-work/skill-shift-automation-andthe-future-of-the-workforce [Accessed 22.03.2019]

Cook, J. (2010). Mobile phones as mediating tools within augmented contexts for development, International Journal of Mobile and Blended Learning 2(3):1-12. 
Ferguson, R., Coughlan, T., Egelandsdal, K., Gaved, M., Herodotou, C., Hillaire, G., Jones, D., Jowers, I., Kukulska-Hulme, A., McAndrew, P., Misiejuk, K., Ness, I. J., Rienties, B., Scanlon, E., Sharples, M., Wasson, B., Weller, M. and Whitelock, D. (2019). Innovating Pedagogy 2019: Open University Innovation Report 7. Milton Keynes: The Open University. https://iet.open.ac.uk/file/innovating-pedagogy-2019.pdf [accessed 23.03.2019]

Hobbs, M., Holley, D. (2016). Using augmented reality to engage STEM students with an authentic curriculum. EAl endorsed Transactions on e-Learning, 3:11. doi:10.4108/eai.15-62016.151447.

Karakus, M., Ersozlu, C., Clark, A.C. (2019). Augmented Reality Research in Education: A Bibliometric Study. EURASIA Journal of Mathematics, Science and Technology Education 15, p.10.

Sutherland, I. (2009). Augmented reality: "The ultimate display", re-edited with permission in Wired.com. https://www.wired.com/2009/09/augmented-reality-the-ultimate-display-byivan-sutherland-1965/ [accessed 22.03.2019]

Wang, M., Callaghan, V., Bernhardt, J., White, K., Pena-Rios, A. (2018). Augmented reality in education and training: Pedagogical approaches and illustrative case studies, Journal of Ambient Intelligent Human Computing 9:1391-1402.

Wu, H.K., Lee, S.W.Y., Chang, H.Y., Liang, J.C. (2013). Current status, opportunities and challenges of augmented reality in education, Computers \& Education, 62, 41-49.

https://doi.org/10.1016/j.compedu.2012.10.024 